\title{
Aortic Origin of Left Vertebral Artery: A Case Report
}

\author{
Mamata S*, Srikanta KM and Sarita B \\ Department of Anatomy, VSS Institute of Medical Science and Research, India \\ *Corresponding author: Dr Mamata Sar, Associate Professor, Department of Anatomy, \\ VIMSAR, Burla, India, Tel: 9439038850; Email: mamatasar@gmail.com
}

\section{Case Report}

Volume 2 Issue 2

Received Date: June 22, 2018

Published Date: June 26, 2018

\section{Abstract}

Objective: To study the abnormalities associated with origin and course of vertebral artery and to discuss the embryological \& clinical significance.

Method: Cadaveric dissection of superior mediastinum showed an abnormal branching pattern of arch of aorta. In addition to the normal branches an extra artery was found to be arising from the arch of aorta in between left common carotid and left subclavian artery. We traced this artery to the neck to describe its course and relation.

Observation: The left vertebral artery instead of arising from left subclavian artery took origin from arch of aorta proximal to the left subclavian artery. The artery had a long prevertebral course before entering into the transverse foramen of fourth cervical vertebra instead of sixth.

Conclusion: Patients with neurological symptoms and those undergoing surgery in neck and chest region should be carefully screened for an aberrant origin of vertebral artery. The aortic arch branching pattern has to be taken into consideration before any manoeuvre in the local region, so as to avoid any unexpected event in relation to aberrant vertebral artery.

Keywords: Arch of aorta; Vertebral artery; Subclavian artery; Foramen transversarium

\section{Introduction}

Normally vertebral artery arises from ipsilateral subclavian artery and passes through the foramen transversarium of all the cervical vertebrae except seventh. It enters the cranium via foramen magnum and at the lower pontine level joins with its fellow to form basilar artery. Occasionally it may enter the vertebra at the fifth, fourth or seventh cervical transverse foramen [1].
During routine dissection we found a case, where the left vertebral artery had an abnormal origin from arch of aorta proximal to the origin of left subclavian artery. The artery took a longer course in the neck before entering into the foramen transversarium of $4^{\text {th }}$ cervical vertebra instead of $6^{\text {th }}$.

Usually these types of arterial variations do not give rise to any clinical problem only to be detected incidentally during radiological examination for some 
other reason. Detection of this type of arterial variation is important for preventing complications associated with head and neck surgery or endovascular procedures of aorta and its branches. Unless aware of this variation during surgical incision in deep cervical region one may damage an abnormally long prevertebral segment of vertebral artery.

\section{Case Report}

During routine dissection in a 50 year old male cadaver we observed that the aortic arch gave rise to four branches. The brachiocephalic trunk, left common carotid and left subclavian artery were in normal position. A fourth vessel was noticed to be arising from aortic arch proximal to the left subclavian artery. Further dissection, tracing the extra artery into the neck revealed it to be the left vertebral artery. The left vertebral artery had a long superficial course in the neck compared to a normal vertebral artery. It ran parallel to the left common carotid artery up to $4^{\text {th }}$ cervical vertebral level where it entered into the foramen transversarium. The left subclavian artery did not give any vertebral artery . Right vertebral artery took origin from right subclavian artery.

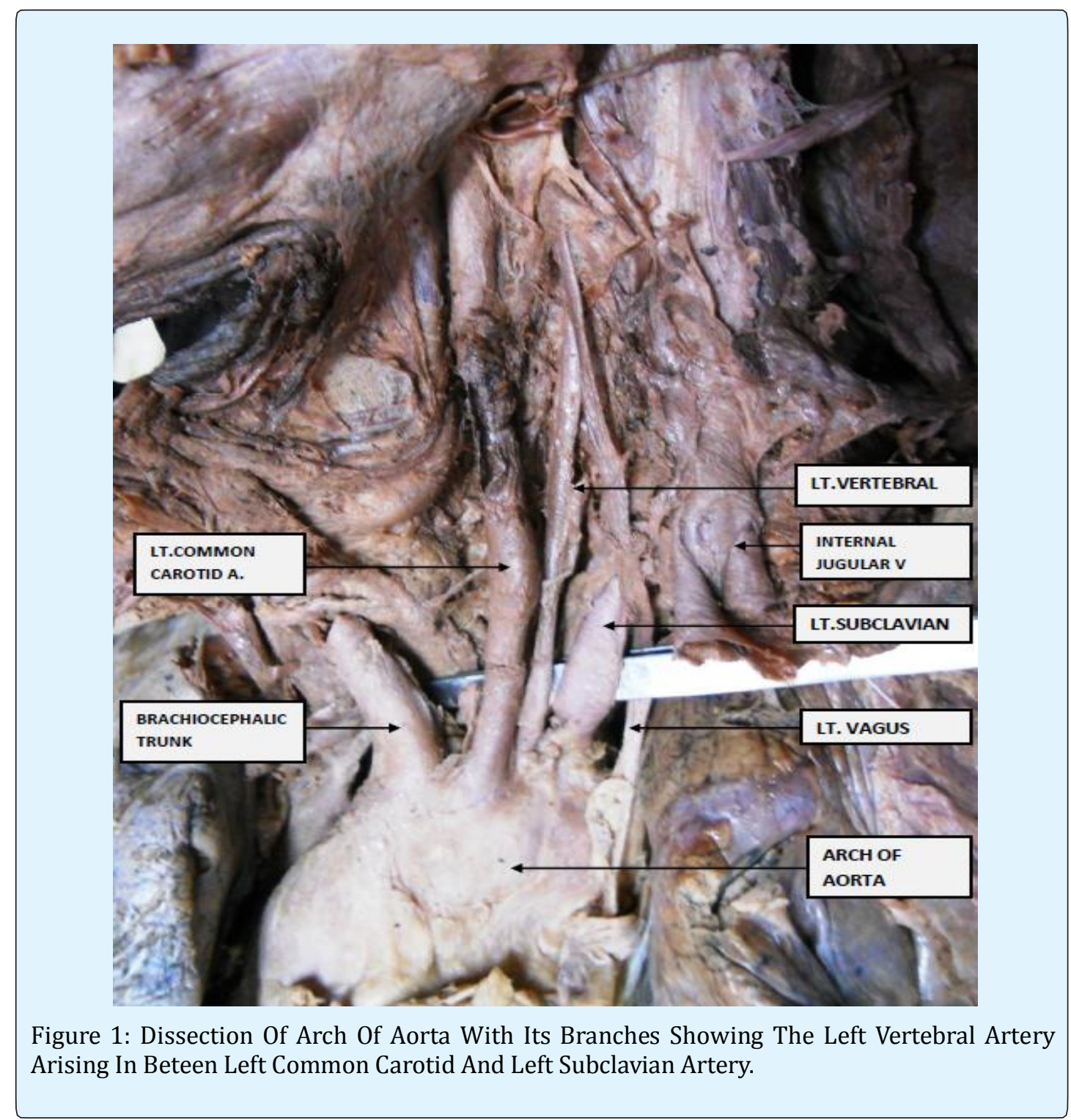

Mamata S, et al. Aortic Origin of Left Vertebral Artery: A Case Report. J Human Anat 2018, 2(2): 


\section{Discussion}

Normally, vertebral artery arises from ipsilateral subclavian artery as its first branch. However multiple variations in origin have been reported by various authors. It may arise directly from aortic arch, common carotid, internal or external carotid or any branch of subclavian artery. The most frequent variant among them is left vertebral artery arising directly from arch of aorta. The site of origin may be proximal or distal to the left subclavian artery. The former is more prevalent than the later. Contrary to left vertebral artery variation in origin of right vertebral artery is rare [2].

In embryonic life the $7^{\text {th }}$ cervical intersegmental artery develops into subclavian artery, the proximal part of its dorsal branch becomes the $1^{\text {st }}$ part of vertebral artery and the longitudinal postcostal anastomosis between all the cervical intersegmental arteries becomes the $2^{\text {nd }}$ part.

Incorporation of the proximal part of $7^{\text {th }}$ cervical intersegmental artery into arch of aorta may lead to direct aortic origin of left vertebral artery [3].

Except the $7^{\text {th }}$ all other cervical intersegmental arteries disappear. Persistence of $6^{\text {th }}$ cervical inter segmental artery may also be responsible for this abnormal origin of left vertebral artery from arch of aorta [4].

Shi-Min Yuan, et al. reported from a cohort study involving 955 patients and 331 cadavers that such type of variation is more common in left than right and more unilateral than bilateral, often asymptomatic, only 5.5\% have symptoms probably related to aberrant origin of vertebral artery [5].

Evan $\mathrm{H}$ Einstein et al. dissected 27 cadavers and found this anomaly in 4 cases and all were female showing a female prevalence [6]. Female prevalence has also been reported by Nayak SR, et al. Contrary to this we found this variation in a male cadaver.

In the present case the abnormal left vertebral artery had a long prevertebral course which entered foramen transversarium of $4^{\text {th }}$ cervical vertebra instead of $6^{\text {th }}$. Uchino et al. noted that most left vertebral arteries with direct aortic origin proximal to left subclavian artery entered C4 or C5 foramen transversarium and all left vertebral arteries with direct aortic origin distal to left subclavian artery entered C7 [7].
Meila et al. reported left vertebral artery originating from aortic arch entered C4, C5 or C7 but never at C6. The longer prevertebral course may lead to increased vulnerability of the vessel wall to shear stress resulting in intimal tear and dissection. According to Komiyama et al left vertebral artery of aortic origin showed a higher incidence of arterial dissection than left vertebral artery of normal origin. They also observed that left vertebral artery with aortic origin enters $\mathrm{C} 4$ or $\mathrm{C} 5$ foramen transversarium $[8,9]$.

This type of arterial variation may remain asymptomatic only to be detected incidentally during radiological examination performed for some other causes. Detection of this type of variation is important to prevent complications associated with surgery or endovascular procedures of aorta and its branches as well as thoracic and head \& neck surgery. Surgeons should be aware of such variations because during surgical incision of deep cervical region there is chance of damage to an abnormally long first part of vertebral artery.

\section{References}

1. Standring S (2008) Gray's Anatomy. The anatomical basis of clinical practice. $40^{\text {th }}$ edition London:Elsevier, Churchill Livingstone Edinburgh.

2. Ergun E, Simsek B, Kosar PN, Yılmaz BK, Turgut AT (2013) Anatomical variations in branching pattern of arcus aorta:64-slice CTA appearance. Surg Radiol Anat 35(6): 503-509.

3. Manyama M, Rambau P, Gilyoma J, Mahalu W (2011) A variant branching pattern of the aortic arch: a case report. J Cardiothorac Surg 6: 29.

4. Nayak SR, Pai MM, Prabhu LV, Sujatha DC, Prakash S (2006) Anatomical organisation of aortic arch variations in India: Embryological basis and review. J Vasc Bras 5(2): 95-100.

5. Yuan SM (2016) Aberrant Origin of vertebral artery and its clinical implications. Braz J Cardiovasc Surg 31(1): 52-59.

6. Evan HE, Linda HS, Natalia LAV, Gregory B, FasaniFeldberg, et al. (2016) Anomalous origin $\mathrm{f}$ left vertebral artery from aortic arch. Aorta (Stamford) $4(2)$ : 64-67.

7. Uchino A, Saito N, Takahash M, Okada Y, Kozawa E, et 


\section{Journal of Human Anatomy}

al. (2013) Variations in the origin of vertebral artery and its level of entry into the transverse foramen diagnosed by CT angiography. Neurocardiology 55(5): 585-594.

8. Meila D, Tysiac M, Peterson M (2008) Origin and course of extracranial vertebral artery: case reportand embryology. J Neuroimaging 18(2): 173176.

9. Komiyama M, Morikawa T, Nakajima H, Nishikawa M, Yasui T (2001) High incidence of arterial dissection associated with left vertebra artery of aortic origin. Neurol Med Chir (Tokyo) 41(1): 8-12.

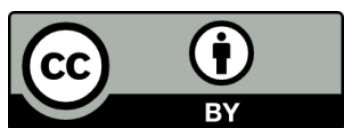

